\section{District of Columbia}

The 22 March 1995 meeting was held at the National Aeronautics and Space Administration (NASA) Goddard Space Center, Greenbelt, Maryland. The meeting had 47 people in attendance.

Ron Gird, chapter chairperson, started the meeting by welcoming everyone. Gird introduced the guest speaker, David S. Leckrone. Leckrone has been a NASA senior project scientist for the Hubble Space Telescope since 1992 and has been with NASA since 1969. He was the recipient of the NASA Exceptional Achievement Medal in 1992.

Leckrone kicked off his presentation by giving an overview of Edwin P. Hubble, a U.S. pioneer in astrophysics who lived from 1889 to 1953. Leckrone mentioned that the Hubble space telescope was launched in April 1990 and then discussed the Hubble space telescope program.

According to Leckrone, initially, the telescope was not able to focus correctly; it needed to be optimized. The problem was the perfectly ground mirror on the Hubble. There was a spacing error that was not caught before launch-too much glass was taken off. The mirror was too flat, and no light was reflected from the inner part of the mirror.

Leckrone said that the Hubble space telescope was planned as a 15-year mission. The design called for service to be provided by astronauts. On 2 December 1993, the space shuttle Endeavor was launched from the Kennedy Space Center with spare parts for repair. Leckrone showed some photos of the astronauts placing parts on the telescope and making corrections. Endeavor landed at the Kennedy Space Center on 13 December 1993. The Goddard Space Flight Center was responsible for overseeing how well the corrections worked on the telescope. The results were visible within a few days. Leckrone then showed the movie: "Hubble Telescope: The Best Is Yet to Come." The movie showed the new camera installed in the telescope.

Leckrone showed some photographs taken by the Hubble Telescope: the first observations of the planets Venus and Mars, a faint object spectrograph picture, the Orion nebula, a star in the process of dying, and remnants of gas from a leftover star. The photos also showed the orbit of a comet that crashed into the planet Jupiter in July 1994 creating a series of explosions at the planet surface.

The winner of the NOAA weather radio was Carmen Tarbell; the radio will be donated to a local church in Fairfax County.
Thirty-five members attended the 26 April 1995 meeting, which was held at the National Weather Service (NWS) Washington Weather Service Forecast Office (WSFO), in Sterling, Virginia.

Dave Pace, chapter vice chairperson, started the meeting by welcoming everyone. Before introducing the meeting's host, Pace announced that Kathryn Sullivan, NOAA chief scientist, will be the guest speaker at the science fair awards banquet. Pace introduced and thanked Jim Belville, the meteorologist-in-charge at the Washington WSFO, for hosting the meeting. Pace mentioned that the NWS had announced that $\mathrm{Jim}$ Belville had been selected as the new director of the OSF at Norman, Oklahoma. His replacement at the Washington WSFO will be Jim Travers.

Belville welcomed the chapter members and introduced some background information about the Washington WSFO. He explained that the site has been in existence since 1944 and is the primary test bed for the NWS observation equipment. Belville introduced Bill Samur, the warning coordination meteorologist for the state of Virginia. He said that the site has close ties to the amateur radio community-SKYWARN, a spotter program that facilitates the pass of severe weather information. Belville introduced the guest speakers, Dan Gropper and Jorge Thevenet.

Thevenet, amateur radio coordinator for SKYWARN, led the presentation. He said that SKYWARN is a free service that has approximately 1000 trained skywatchers. The area of responsibility covers a 10000 -square-mile radius within the states of Maryland, Virginia, and West Virginia. Regional subnets include Washington, northern Shenandoah Valley, southern Shenandoah Valley, Charlottesville, and southern Maryland. Thevenet explained that the activation of the network is made by the Sterling lead forecaster-the amateur radio net is activated within $5 \mathrm{~min}$ of the forecaster's call. The network rebroadcasts the NOAA weather radio warnings. A hurricane net is also available, and an extra set of radios are activated for this purpose. During the 1993 storm of the century, the forecasters started operations on a Saturday at 5:00 A.M., and by noon Sunday, the only concern was drifting snow. Over this period of time, SKYWARN made more than 980 reports on amateur radio. The SKYWARN manning at the Washington WSFO required two people to take the calls.

Thevenet mentioned that SKYWARN has scripts for different situations. The scripts cover winter, summer, flooding, and hurricanes. In the winter, some of the concerns are snow accumulation over 4 in., severe 
icing on trees, and winds over $30 \mathrm{mph}$. In the summer, the concerns are hail, winds over $50 \mathrm{mph}$, flooding, rain accumulation over 1 in., damage by wind or lightning, and downed trees on power lines.

The way the SKYWARN network is setup, one office covers more than one state, crossing political boundaries, which, explained Thevenet, is a situation that is becoming more common. An example portraying this situation happened in the state of Alabama. The amateur radio operators helped the NWS offices in Birmingham and Huntsville for approximately two hours after a lightning strike. They provided emergency communications service during a period of need.

SKYWARN uses an activation checklist for severe weather situations. The NWS forecaster briefs the SKYWARN amateur radio coordinator on the need for activation, the start time of the event, the expected duration, the timing (e.g., Shenandoah Valley by 2:00 P.M., Chesapeake Bay by 6:00 P.M.), the anticipated scope of impact (how much of the area will be held), and any special needs (e.g., overnight stay, spotter at bridges for high water). The SKYWARN amateur radio coordinator then uses this information to alert the subnets, the SKYWARN repeater is put into a net mode, arranges for the net control to be established at the Washington WSFO, and arranges for relief. The meeting concluded with a question-and-answer session and a tour of the Washington WSFO.

There were some questions on training for the spotters. Belville informed the group that training classes are offered at the WSFO, at which 300 to 400 spotters are trained per year. The classes meet on average twice a week (three to four hours per class), and there is space for five spotters per class.

The winner of the April meeting's drawing for the NOAA weather radio was Dirk Herkof, chapter member.

On 17 May 1995, 16 chapter members convened to listen to Rocky Lopes, of the American Red Cross, deliver his presentation.

Lopes gave a brief overview of the American Red Cross in the Washington, D.C., area. He said that the American Red Cross office was moved from Washington, D.C., to Falls Church, Virginia, but the head of the Red Cross, Elizabeth Dole, still maintains an office in Washington, D.C. He mentioned that the Red Cross has a large volunteer pool of which he has served for 22 years.

The job of the Disaster Headquarters', where Lopes

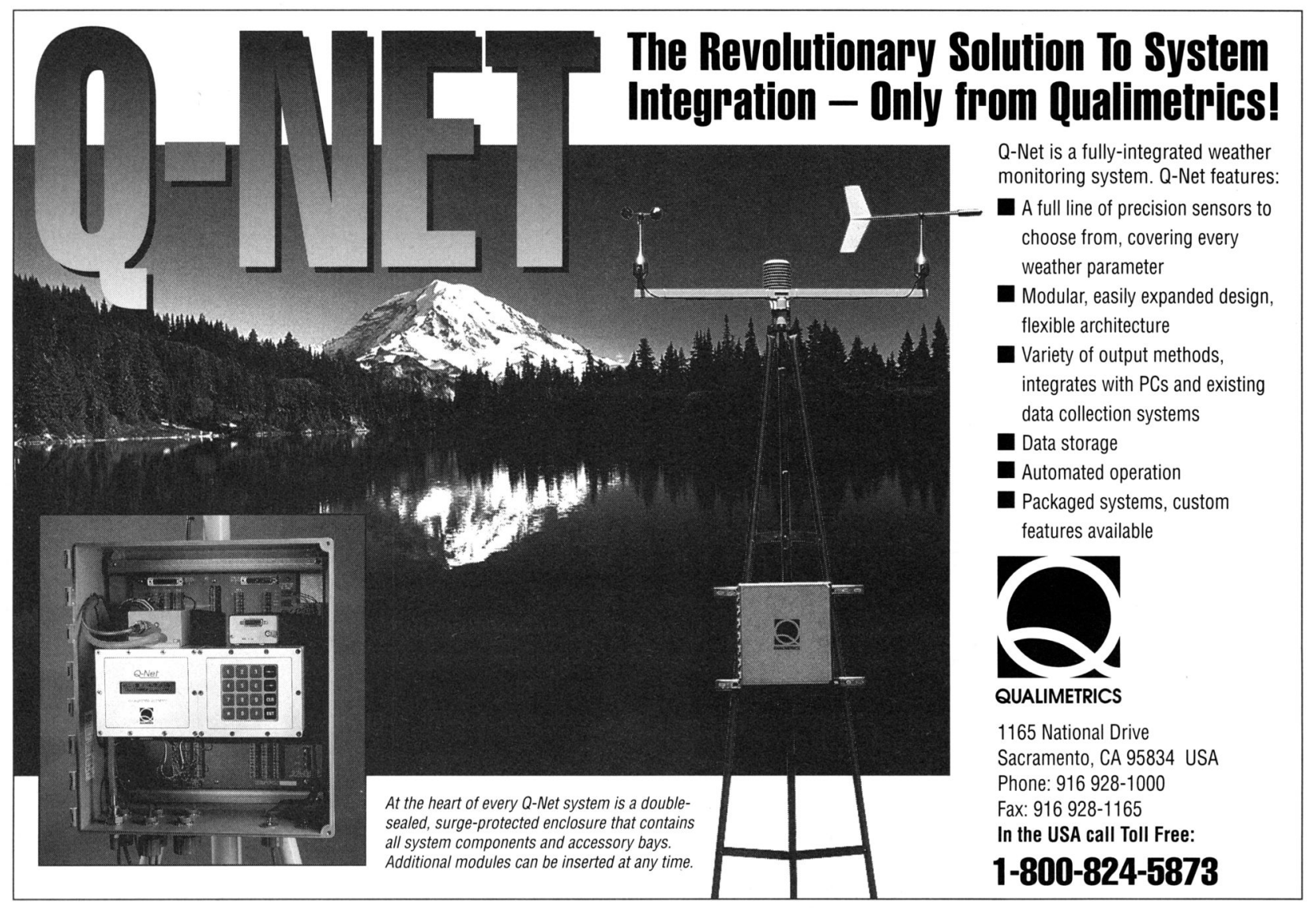


works, is to convince people to do something they normally would not do-for example, experiencing a hurricane disaster. To illustrate this example, Lopes brought a few joint agency brochures showing what to do in a hurricane, a tornado, and a snowstorm.

Lopes explained that research has demonstrated that with the public, if they believe something can happen, they do not know what to do about it. If an earthquake happened now, many people would most likely react as they think they should. Most people would try to leave the building that they are in, which is the most dangerous thing-being 10 feet outside of the building. According to Lopes, the most appropriate action to take would be to drop to the floor, take cover, and stay still. Unless people practice this option, it does not stay in their memory.

The American Red Cross is funded by donations from the public, corporations, the United Way, and the Combined Federal Campaign nationwide. The organization interfaces with people in different circumstances. The American Red Cross, along with the Federal Emergency Management Agency (FEMA) and NOAA, worked on a coalition that grew to produce specific brochures to keep the public better informed. The coalition concentrated on what the public needed to know, why they needed to know, and what would cause behavior modification. NOAA created a 10page color brochure on winter storms and the American Red Cross printed a 1-page brochure on winter storms. The artwork in the brochures shows the right things to do in the event of a winter storm; it reinforces the correct way. Both agencies exchange and trade information.

Discussing tornadoes, Lopes recommended that people go to the lowest point in their home, an area with no windows, in the event of an occurrence. Texas A\&M University conducted a study in an area where disaster instruction brochures were widely available. The results showed that $80 \%$ of the people involved did the right thing by recalling the information available in the tornado brochures.

Lopes said that he views his job at Disaster Headquarters as one of action and behavior change. The American Red Cross has been very successful with printed materials, which have reached approximately 48 million people.

Dave Pace concluded by thanking Rocky Lopes for his presentation and presented him with an AMS mug.-Carmen H. Tarbell.

\section{Greater St. Louis}

Approximately 50 members and guests convened at KSDK-TV Channel 5 in St. Louis for the regular monthly meeting. Chapter Vice President Rich Woodford gave a special welcome to the three win- ners from the local science fair as well as their family members.

Woodford reminded attendees that one of the goals of the AMS is to promote meteorology and science education in the local community. This is the basis for the chapter's involvement in local science fairs. He then yielded the floor to Chapter Past-President John Louer, representing Science Fair Committee Chairman Ken Walters. Louer then introduced and honored those chosen to receive awards from the AMS based on their participation in the recent Monsanto/St. Louis Post-Dispatch Science Fair. Louer was assisted by Ed Boselly of Surface Systems, Inc. (SSI), whose company donated some of the prizes. First-place winner was La Quisha Brooks of the Academic and Athletic School. She received an AMS certificate, a subscription to Weatherwise magazine from the chapter, and a weather alert radio. Second place went to the team of Jackie Weiss and Angie Vogel from St. Francis of Assisi School. They received a certificate and the USA TODAY/Weather Book, presented by SSI. Third-place winner Kate Gaston, from Holman Middle School, was not present. She will receive the same prizes as the second place team. Additionally, John Fuller and Scott Connell of KSDK-TV presented each student with the Weather Check instrument package to encourage them to continue their observations of the weather.

Woodford opened the discussion about the Greater St. Louis Chapter 50th Anniversary Banquet by introducing Wayne McCollom, chairman of the banquet committee. McCollom announced a tentative date of 16 November. David Houghton, president of AMS, has agreed to speak to the chapter on that date. After a period of discussion, the spending authority of the executive committee was raised in order to meet expenses related to the banquet.

Ed Boselly was then recognized to speak on behalf of the Planning Committee for the AMS Annual Meeting. He is working on the Symposium on Environmental Applications. He informed the membership that the number of abstracts for this symposium is lacking.

Lou Hull then made a suggestion that, in conjunction with the anniversary banquet, the chapter consider inviting past-presidents of the local chapter for a mini-reunion. The local chapter has had many presidents who have made significant contributions to the science of meteorology and/or held prominent positions within AMS.

Woodford introduced the hosts and speakers for the evening, John Fuller and Scott Connell from KSDK-TV. In brief opening remarks, Connell stressed to the students present that while broadcast meteorology is the most visible branch of the science it is actually one of the smallest. He emphasized the 
broader meteorological sectors that provide information and capabilities for the broadcast sector. The membership then divided into two groups for station tours by the hosts.

The tour included a look at the news studio and the attached weather center. The station uses an automated system to collect, compile, and display weatherrelated school closings for the 800 school districts in the viewing area. There is also an automated system that displays severe weather bulletins on the viewers screen as soon as they are received. KSDK's weather center also manages a local Weather Net with four area schools. The schools' observations are monitored at the weather center and are often used in the broadcast. Students can obtain data from their site as well as the other sites for use in science education and projects. Additionally, the Weather Net aids in the detection and location of severe weather. Plans are to add at least five other schools to the network. While a normal weather broadcast may receive just over three minutes of air time, conditions may dictate that more time be devoted to the weather. In fact, during a severe weather outbreak across the bistate area on 18 May 1995, the weather center provided more than 90 minutes of continuous, live, midday coverage of the situation, tracking storms and funnel cloud sightings, relaying up-to-the-minute warnings, and providing reminders on how to adequately take shelter from the weather. In such a situation, good cooperation between the media and the NWS is crucial.-Norm Modlin.

\section{Mobile Bay}

The last meeting of the season was held at the Mobile NWS Forecast Office on 15 May 1995. Eric Williford, research assistant and Department of Energy computational science graduate fellow at The Florida State University (FSU), was the invited speaker. He presented a lecture entitled "Numerical Modeling of Tropical Cyclones."

Williford began with a broad overview of tropical cyclone characteristics and formation processes. This included some discussion of the roles of the TUTT and CISK as well as approaches to numerical quantification such as angular momentum and kinetic energy budgets. He then described T. N. Krishnamurti's FSU global spectral model used for the research of tropical cyclone dynamics. The model includes a modified Kuo cumulus parameterization, shallow convection, radiative fluxes, a dry convective adjustment, and other

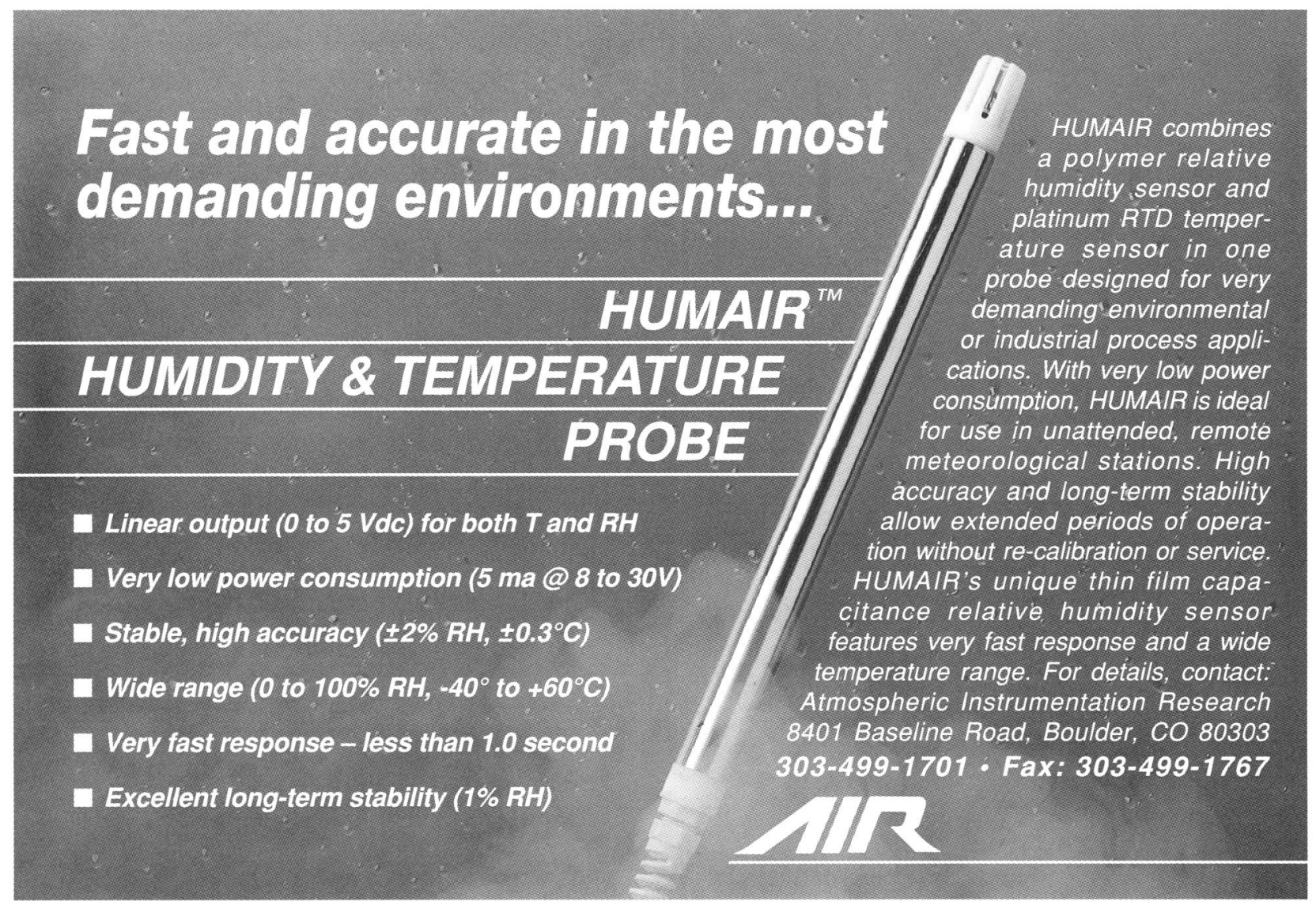


Editor's note: The "About our Members" feature of the August 1970 Bulletin included, among others, the following items:

Jule Charney of MIT spoke at seminars on "The observability and predictability of global atmospheric systems" at Oregon State University on 23 and 24 April. These seminars were part of a special series marking the first year of the new Department of Atmospheric Sciences at the university.

Thomas S. Moorman, superintendent of the Air Force Academy, Colorado Springs, retired from the Air Force 1 August after more than 37 years of military service. For more than 20 years of a military career that began with graduation from West Point in 1933, Gen. Moorman was

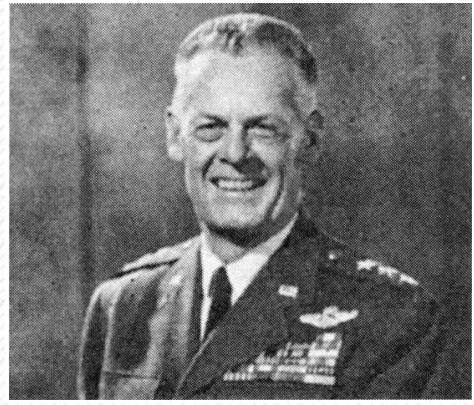

Thomas S. Moorman a weather officer. His commands have included the 2343 Air Wea. Wg., Tokyo, Japan; Air Weather Service; Hq. 13th Air Force; and vice commander in chief of Hq. Pacific Air Force, USAF. He received the master's degree in meteorology in 1938 from California Institute of Technology and did graduate work at Massachusetts Institute of Technology in 1941. He is representative to the Meteorological Committee of the NATO Standing Group, a Fellow of the AMS, a member of the Association of American Colleges and the National Education Association, and an active promoter of Scouting. He holds many military decorations, including the Distinguished Service Medal, the Legion of Merit with two oak leaf clusters, and the Croix de Guerre with palm from France, Belgium, and Luxembourg. The general and his wife plan to stay in the Colorado Springs area at least temporarily and hope to become active in environmental studies.

Walter Orr Roberts, president of the University Corporation for Atmospheric Research, was elected a trustee of the Aspen Institute for Humanistic Studies. The Institute offers an executive program which provides an intensive two-week series of daily seminars based on humanistic readings, and conferences for leaders in education and science.

Bull. Amer. Meteor. Soc., 51, 747-750.

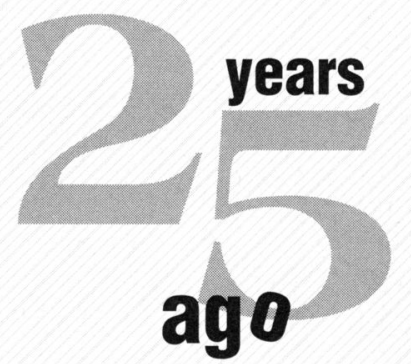

features. It is able to show tropical cyclone characteristics, such as the theta $e$ minimum at $700 \mathrm{mb}$, and the structure of the vortex and its surroundings.

More importantly, the model includes a physical initialization procedure (during data assimilation) to allow for proper environmental spinup (including tropical cyclones) by day zero. Williford explained that this initialization procedure is accomplished by using reverse algorithms consistent with the physics of the numerical model to match observed fields, such as outgoing longwave radiation (OLR) and observed rainfall, to model rainfall and mode-based OLR, sensible heat fluxes, and wind fields. This provides for a realistic tropical system that interacts with the surrounding model environment and improves longerrange forecasts. Good results have been shown in tropical cyclone case studies using this technique.
Williford also discussed the issues involved in forecasting tropical cyclone movement and intensification. Steering currents are important and often allow climatology/persistence-based models to do well in track forecasts. Although dynamical model attempts do sometimes capture the essence of cyclone changes, the proper diagnosis of the initial environment, the vortex structure, and the outflow of the storm are crucial for these to be successful. Williford briefly described the operational models used by National Centers for Environmental Prediction and the Tropical Prediction Center (formerly the National Hurricane Center) and illustrated their relative skill.

Following his presentation, Williford discussed a poster presentation on Tropical Storms Alberto and Beryl that he had presented at the 21st Conference on Hurricanes and Tropical Meteorology in Miami, Florida, 
in April. He explained how WSR-88D observations, and postanalysis of those observations, provided greater insight into storm structure and dynamics. They also provided a case study for the improvement of operational use of Doppler information during a tropical event. The poster presentation is available for viewing on the World Wide Web at [http:// thunder.met.fsu.edu/ citm] under "research topics." -Paul Croft.

\section{Los Angeles}

Members attended the annual awards banquet on 20 May 1995. The chapter awarded Richard Dickert, president of California Weather Enterprises, a plaque for "contributions to the field of meteorology" through his 1995 weather calendar "Southern California Does Have Weather." Charles and Marilyn McClellan, who have served as secretary and treasurer, respectively, were presented with an Ansel Adams framed photograph, depicting Yosemite in winter, for their many years of service to the chapter.

Banquet speaker, Mike Wofford, aviation forecaster at the Los Angeles Weather Office in Oxnard, gave a presentation on the NEXRAD Doppler radar. -Steve LaDochy.

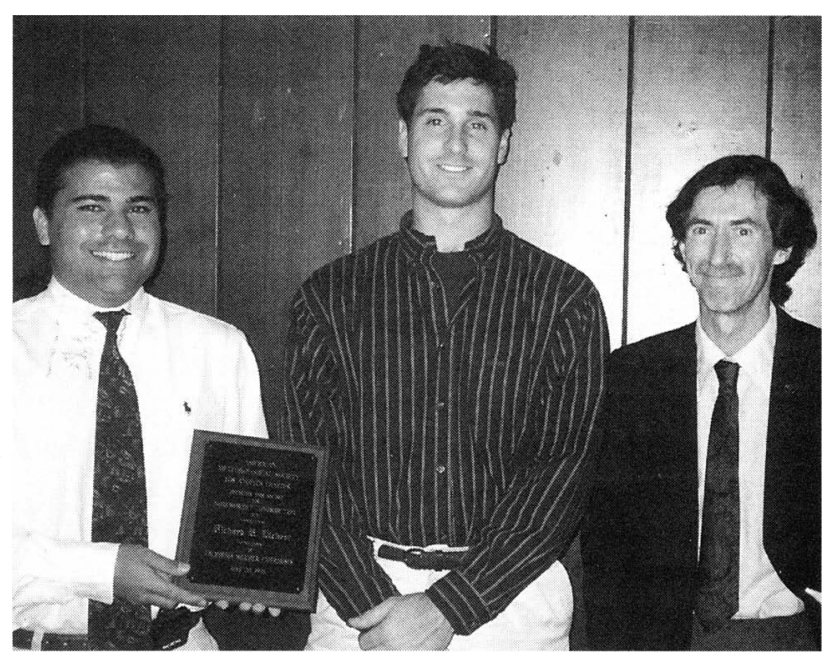

From left to right, Richard Dickert, Los Angeles chapter award winner; Mike Wofford, banquet speaker; and Steve LaDochy, outgoing chapterchairperson.

\section{GOES-8 \& 9 GVAR Multi-Tasking Desktop System}

Did you ever dream of owning a Very High Resolution, desktop ingest and display system but felt it was out of your reach? Finally, hear is the system for you that displays the weather the way you want it, when you want it at an affordable, down to earth price. This superb, Multi-tasking Desktop system, can display all channels of the GOES-8 \& 9 satellite including channels $2,3,4,5, \&$ Visible. No other system can give you such superb quality plus price/performance on one computer. Extremely easy click \& point window type operation producing a very user friendly system. Data retrieval is seamless while ingesting, animating, printing, scrolling, viewing etc, all simultaneously under our Multi-tasking platform. This is a high quality, professional, ingest \& processing system for those in a demanding environment requiring weather data immediately with unbelievable clarity. Be a proud owner of this magnificent very high resolution 1280 X 1024 X 256 imaging system.

SYSTEM: $\quad \cdot 90 \mathrm{Mhz}$ Pentium $\bullet 32 \mathrm{Meg}$ Ram $\bullet$ SCSI controller $\bullet 425 \mathrm{Meg}$ Drive C $\bullet$ Integrated Feed/Downconverter $\cdot$ XGA Video Card • 2 Gbyte D Drive $・ 17 "$ Monitor $・ 1.44$ Meg Floppy • Serial Mouse • Bias T Pwr $\cdot 100$ ' Cable • Keyboard • Demodulator Card • Frame Formatter Card • 14.5' Mesh Dish \& more.

SOFTWARE: Scientific software package capable of Ingesting, Viewing, Histogram Display, Zooming, Printing, Sectorizing, Geopolitical Boundaries, Gridding Lat/Lon, Colorization, Multi-Spectral Water Vapor, High Low \& Median Filtering, Range \& Distance, User defined palettes, Looping, True Aspect Ratio Correction up to 20:1 and much more. Please write, phone or fax for more descriptive information.

Complete U.S.A. system price excluding shipping \$19,500.00

GTI Electronics 1541 Fritz Valley Rd Lehighton, PA 18235 717-386-4032 Fax 717-386-5063 Internet E-Mail gtielect@postoffice.ptd.net International call 301-855-1214 Fax 410-535-6148 